\title{
Paraplegia
}

\section{Cervical Spine Injuries: A Follow-up of 332 Patients}

\author{
H. Ersmark, MD, N. Dalen, R. Kalen \\ Department of Orthopaedic Surgery, Danderyd Hospital, S-182 88 Danderyd, \\ Sweden.
}

\section{Summary}

A follow-up of 332 consecutive cervical spine injury patients is described. Treatment was with collars (47\%), operation ( $6 \%)$, skull traction ( $24 \%)$ and Halo vest $(23 \%)$. There was a large number of cervical spine injuries at the C2 level, and odontoid process fractures constituted 35\% of all cervical spine injuries. The bad reputation of cervical spine injuries with high mortality rates, high non-union rates, and a high incidence of severe neurological impairment could not be confirmed. Traffic accidents affected the younger age categories, and injuries from falls the older ages. The accidents occurred in $95 \%$ during leisure, and at least $22 \%$ of the patients were under the influence of drugs and/or alcohol. Halo vest treatment gave a low complication rate, a low use of hospital bed days, sick leave and disability pension, compared with operations and skull traction treatment. The complication rate associated with the skull traction and operative treatment was unacceptably high.

Key words: Cervical spinal injuries; Follow-up study.

In the nineteenth century, the diagnosis of a cervical spine injury was made at autopsy in criminals with a fracture dislocation of the axis who had been executed by hanging. As non-invasive investigation methods such as radiography did not exist before 1895, cervical spine injuries were regarded as rare and fatal. The interest of these injuries was initially focused on the upper cervical region (Mixter and Osgood, 1910; Fritzsche, 1913; Jefferson, 1920; Osgood and Lund, 1928). They could only be diagnosed at post-mortem and therefore had a bad reputation.

In later studies, however, mortality rates as low as $4 \%$ have been reported; $5 / 63=8 \%$ (Amyes and Andersson, 1956), 14/77 = 18\% (Rogers 1957) and $1 / 26=4 \%$ (Nachemson 1960), 3/68 = 4\% (Althoff 1979).

The first publication of a patient treated by an operation was a patient with delayed union of an odontoid fracture (Mixter and Osgood, 1910). The posterior arch of the atlas was stabilised with the spinous process of the axis with silk. 
Later many series were published regarding operative treatment of cervical spine injuries (Cone and Turner, 1937; Gallie, 1939; Cloward, 1961; Verbiest, 1969). In 1933 Crutchfield reported on the use of skull traction for a patient with a fracture dislocation of the axis.

A further development of skull traction, the Halo vest, was developed in 1959 by Perry and Nickel to provide support for adult patients with a collapsing spine due to poliomyelitis. The Halo vest consists of a skull ring connected via rods with a jacket. The method was later employed for the immediate treatment of acute fracture dislocations of both the upper and lower cervical regions (Seljeskog, 1978; Thompson, 1962; Cooper et al., 1979).

The aim of this study is to describe all patients with a cervical spine injury between the years 1970-1980, in the Stockholm County Council area.

\section{Material and methods}

The medical records of patients hospitalised for cervical spine injuries were reviewed in 12 hospitals: Serafimerlasarettet, Sabbatsberg Hospital, St Göran Hospital, St Erik Hospital, Södersjukhuset, Karolinska University Hospital, Huddinge University Hospital, Danderyd University Hospital, Södertälje Hospital, Norrtälje Hospital, Löwenströmska Hospital, and the Nacka Hospital. The radiological records of patients who were $\mathrm{X}$-rayed for cervical spine injuries in the same 12 hospitals were also reviewed.

The purpose of selection by both the medical records and the radiological records was to avoid false recordings and missed recordings. The quality of the recordings of diagnosis was not so reliable at the beginning of the 1970s (via punch cards) as at the end (direct via terminals). Therefore this double check was made in order to obtain as exact a collection as possible of the cervical spine injuries. 332 patients were thus studied who had undergone treatment at the departments of general surgery, orthopaedic surgery or neurosurgery in the 12 hospitals.

The records of sick leave, and disability pensions were studied. These data, collected from the Social Insurance Office, were obtained in 191 patients. The remaining group of patients were either too young (16 years not recorded), dead (eliminated from the records), or for some other reason not available in the files, e.g. unemployed.

In the Stockholm County Council there are 5 hospitals with special departments for orthopaedic surgery, 2 with special departments for neurosurgery, and 7 hospitals with general surgery only. Patients with cervical spine injuries were referred to these departments (Fig. 1).

The year and month distribution, age and sex distribution, cervical spine injury distribution, direction of displacement, cause of trauma including the influence of drugs and alcohol, accident at work or during leisure, concomitant injuries classified according to the Abbreviated Injury Scale and Injury Severity Score (Baker et al., 1974; Baker and O'Neill, 1976), choice of treatment, primary neurological impairment, head injury, clinical examination, delay in making a diagnosis, mortality, complications associated with the treatment, healing rate, hospital and post-hospital treatment were obtained from the medical records and radiological records and were recorded on a special trauma form. The differ- 


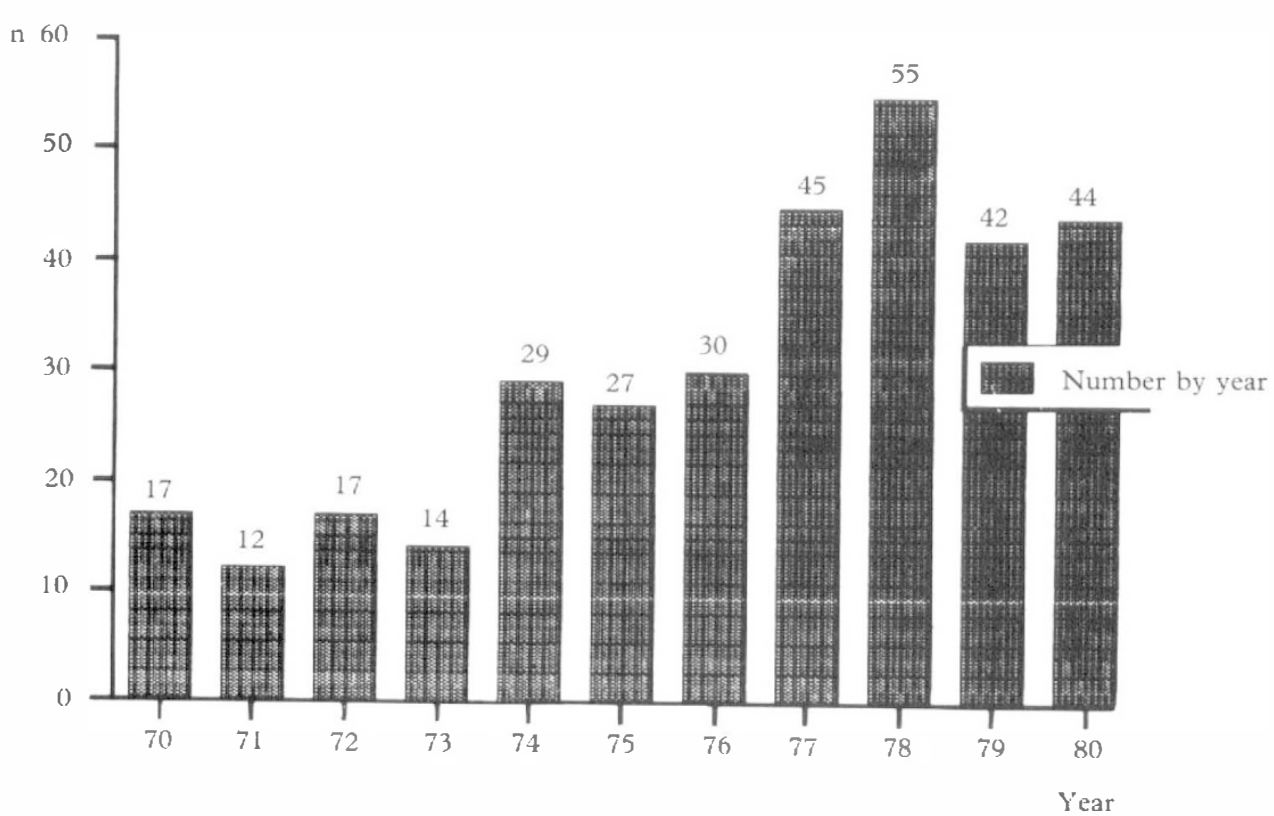

Figure 1 Number of cervical spine injuries by year 1970-1980.

ent parameters which had been collected were coded and analysed with a computer (IBM $3081 \mathrm{~K}$ ).

\section{Results}

The population of the Stockholm County Council area is about 1.5 million. Between 1970-1980 (Fig. 1) there was an increased number of cervical spine injuries. The incidence of cervical spine injuries by months of the year showed a slight tendency to a peak in the summertime. The age and sex distribution showed that most cervical spine injuries occurred at the ages of 20-40 years (Fig. 2). Sixty six per cent were men and 34 per cent women. Only 5\% of the injuries occurred at work, the rest during leisure. The influence of drugs and alcohol was mentioned in $22 \%$ of the medical records.

\section{Cervical spine injuries: distribution, C1-C7}

The analysis of the various types of cervical spine injuries with respect to fractured parts and levels, dislocation injuries with and without fractured parts and their displacement anteriorly or posteriorly, showed a clear peak at the C2 level.

Fractures at the $\mathrm{C} 2$ level were the commonest (Fig. 3) and involved first, the odontoid process; second, the pedicles; and third, the vertebral body. The next common level was $\mathrm{C} 5$ affecting the vertebral body.

The frequency of dislocation injuries (Fig. 4) with and without fractures was most common at level C6-C7, followed by C5-C6, then C2-C3.

The analysis of the displacement anteriorly or posteriorly, showed a greater number with an anterior displacement than posterior. 


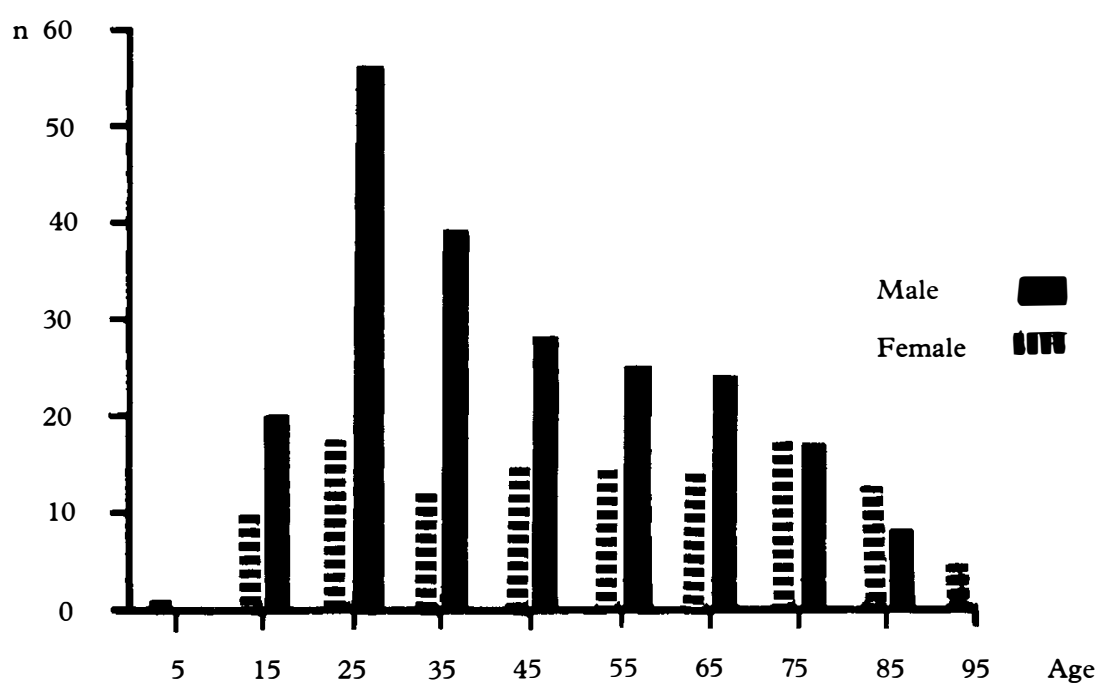

Figure 2 The age and sex distribution of cervical spine injuries.

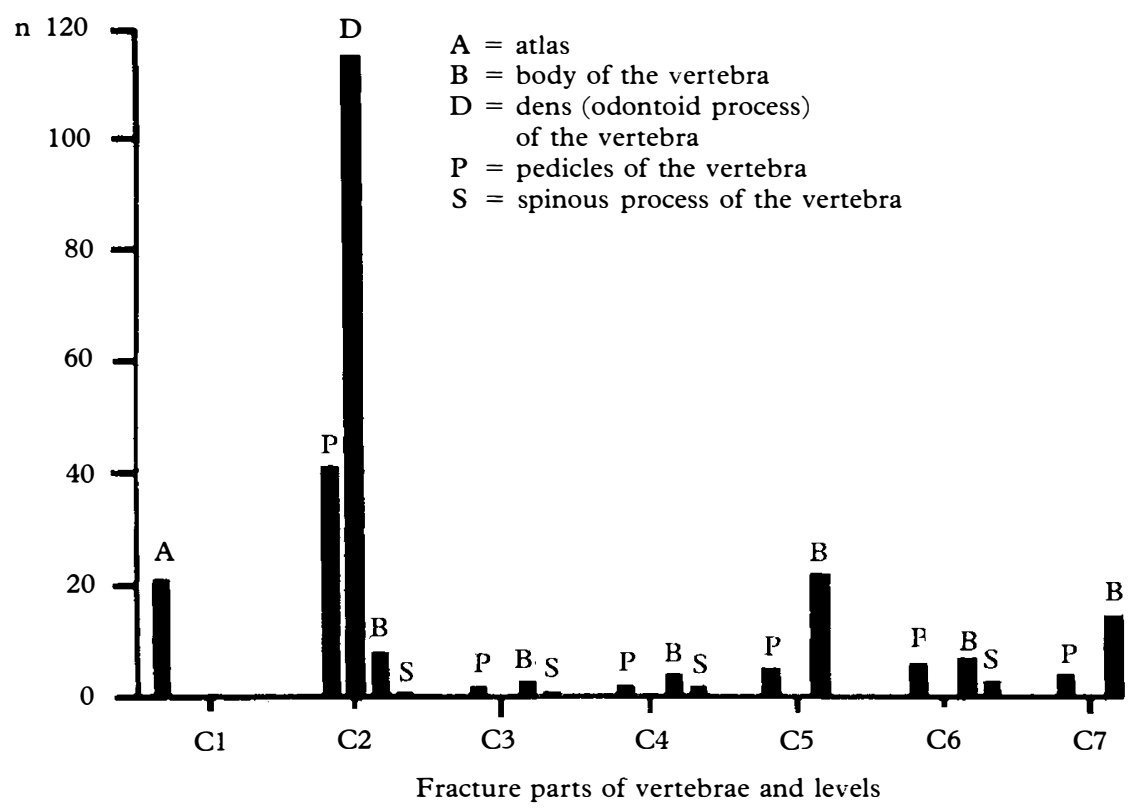

Figure 3 Cervical spine injuries, distribution C1-C7.

\section{Cause of trauma}

Traffic accidents were most numerous $(50 \%)$, next came injuries from falls $(37 \%)$, and third diving accidents $(5 \%)$. Other accidents constituted $8 \%$ (Fig. 5 ). When the subgroups of traffic accidents (car driver/passenger with/without safety belt, bicycle, motorcycle, pedestrian and others) were correlated to the trauma level, the $\mathrm{C} 2$ level was most commonly involved in all of the groups. 


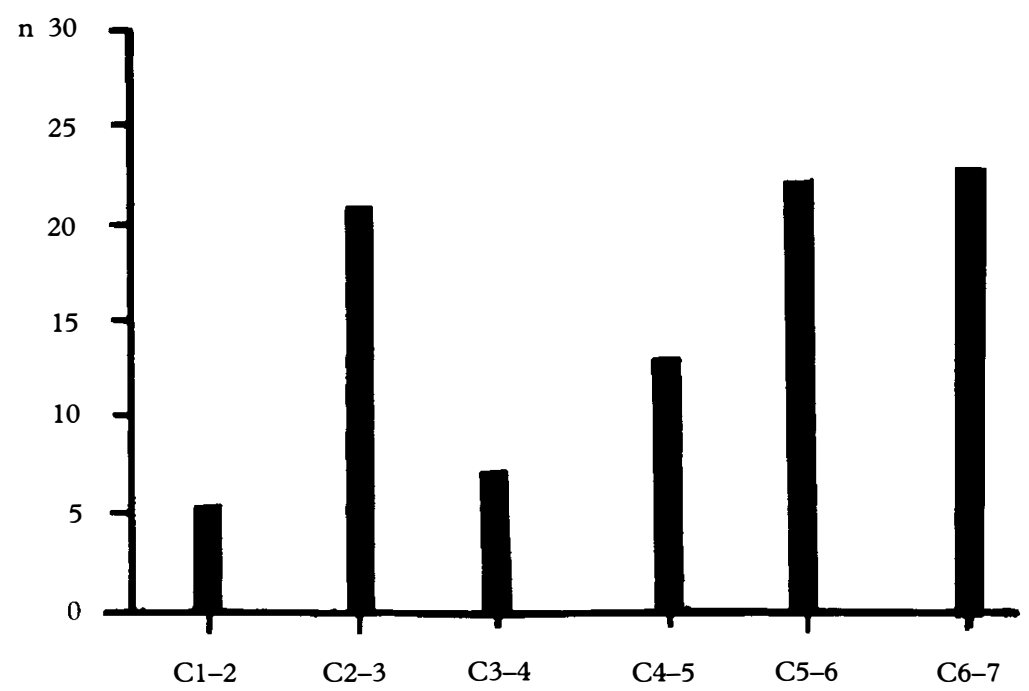

Figure 4 Number of dislocation injuries with respect to level of the cervical spine.

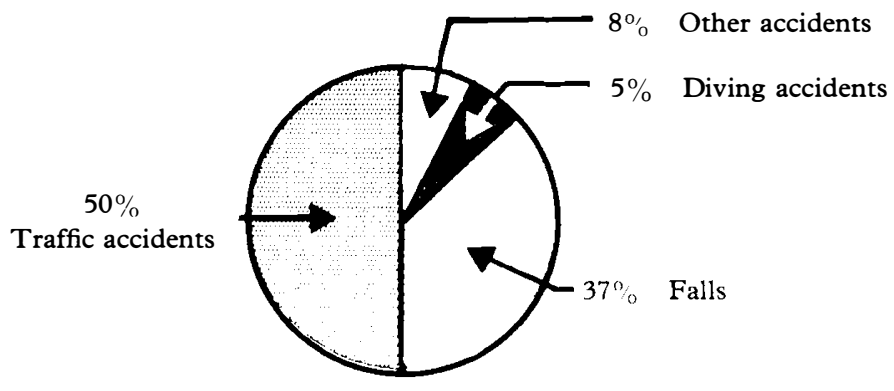

Figure 5 Cause of trauma.

The age distribution showed a peak at around 25 years for all subgroups of traffic accidents. In these subgroups there were no obvious differences concerning sex, except that women were not involved as motorcyclists. The number of traffic accidents by months of the year showed a tendency for a greater frequency for all groups in June, July, October, November, December and January. Traffic accidents occurred during leisure, in $95 \%$. The group 'car driver/passenger' was in $19 \%$ of the medical records classified as intoxicated.

When injuries from falls were correlated to the trauma level, the pattern was the same as with traffic accidents, the C2 level was most commonly involved, regardless if the injuries from falls occurred at the same level or from a height inside-or outdoors.

The age distribution of injuries from falls, except falls from a height outdoors, revealed a greater incidence in older ages in contrast to traffic accidents. A tendency was found for men to fall more from heights and at the same level outdoors. The number of injuries from falls by months of the year showed that fewest occurred in September, and most in March. The subgroups of injuries from falls did not show any other special trend.

Also injuries from falls occurred during leisure in $95 \%$. About $30 \%$ except 


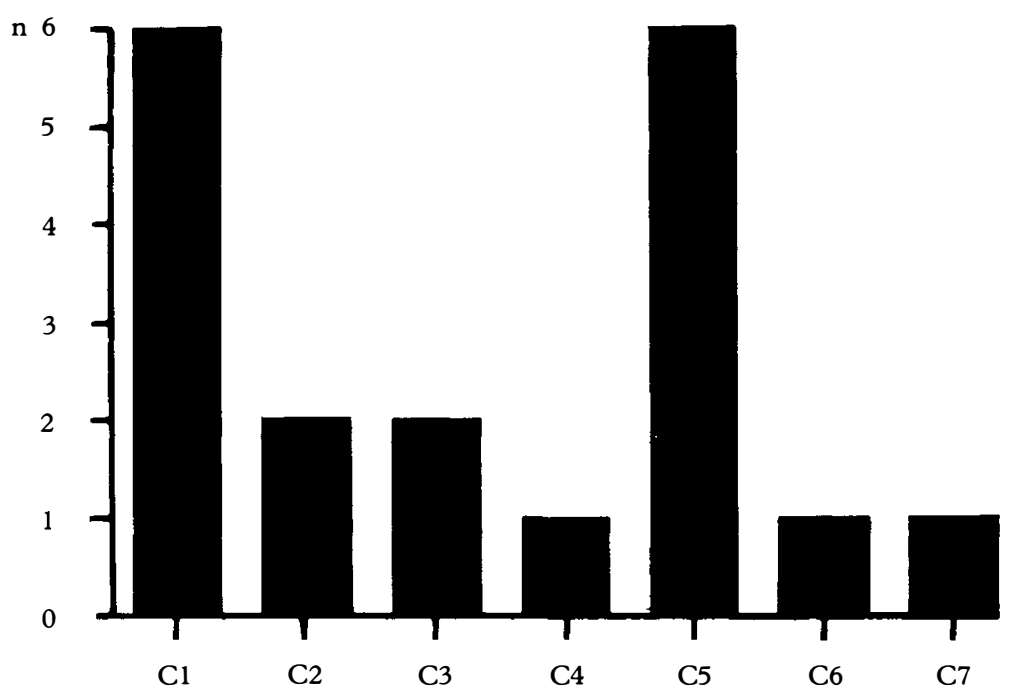

Trauma level of the cervical spine

Figure 6 Number of diving accidents vs trauma level of the cervical spine.

injuries from falls from height indoors, were classified as intoxicated, in the medical records.

Diving accidents occurred most frequently in the summer months, and the most commonly involved levels were $\mathrm{C} 1$ and C5 (Fig. 6). The miscellaneous groups 'others' did not show any special tendency in any direction in our analysis.

\section{Concomitant injuries}

About $20 \%$ of the whole group had concomitant injuries. This was more common in those who had had a traffic accident $(30 \%)$, than in those who had had a fall $(15 \%)$. The concomitant injuries were not usually serious (Injury Severity Score $<25$ ), except for a minor group of multitraumatised patients (Injury Severity Score $>25$ ), where the cervical spin injury was just part of a multiple injury complex.

\section{Primary neurological impairment}

An analysis of the primary neurological impairment showed that $18 \%$ had some type of deficit primarily. Paresthesiae, numbness, transient muscular weaknesses in the upper or lower extremities being the most common $(13 \%)$. Tetraparesis was found in $5 \%$.

\section{What governed the surgeon in the choice of treatment?}

Treatment was with a collar $(47 \%)$, operation $(6 \%)$, skull traction $(24 \%)$ and Halo vest $(23 \%)$. In Table I the different types of operation are listed, and in Table II the different types of skull traction tongs. 
Table I Types of operation $(\mathrm{n}=19)$

\begin{tabular}{ll}
\hline Fusion according to Cloward & $50 \%$ \\
Fusion with methylmethacrylate cement and autogenous bone graft & $34 \%$ \\
Others & $16 \%$ \\
\hline
\end{tabular}

Table II Types of skull traction tongs used $(n=78)$

\begin{tabular}{lr}
\hline Crutchfield & $43 \%$ \\
Blackburn & $20 \%$ \\
Gardner-Wells & $15 \%$ \\
Winke & $14 \%$ \\
Others & $8 \%$ \\
\hline
\end{tabular}

When analysing which factor might have influenced the surgeon in the choice of treatment (concomitant injuries, neurological impairment or displacement), it was found that displacement was the most important factor. In the group treated with a collar only $10 \%$ of the cervical spine injuries were displaced, compared with operation $58 \%$, skull traction $33 \%$, and Halo vest $39 \%$ (Table III).

When the four groups of treatment-collars, operation, skull traction and Halo vest-were analysed according to age and sex, collars and operation were the choice in the younger age categories, while skull traction and Halo vest were more evenly distributed. There were no differences concerning the sex of the patient. Neurological deficits were present in all of the four main groups of treatment. Contusio cerebri was found only in the groups skull traction and Halo vest. In the group of tetraparesis, the C5 level was most commonly involved.

\section{Skull impact (head injuries)—clinical examination-delay}

Skull impact occurred in $42 \%$ of the patients. The most common result was a haematoma/excoriation or a cut wound in the anterior part of the head. Different skull impacts were related to the trauma level in order to investigate whether different types of head injuries would favour any special level. The C2 and C5 level, with predominance of $\mathrm{C} 2$, were the most frequent.

Delay of more than 1 day in making the diagnosis was found in $18 \%$. In two thirds of the patients, it was due to 'patient's delay' and in the remaining third to 'doctor's delay'.

\section{Mortality and complications associated with the treatment}

The overall mortality was $5 \%$. In Table IV the treatment given, the number of days after trauma and the cause of death are listed for the 15 patients who died. It was noted that 9 of these patients were over the age of 65,6 below age of 45 , and none between these ages.

The lowest complication rate associated with treatment was in the group who had collar $(0 \%)$, and next Halo vest $(18 \%)$ (Table V). Skull traction treatment and operations had a high rate of complication associated with the treatment 
Table III Number of displaced fractures in the different groups of treatment

\begin{tabular}{lcccc}
\hline & Collars & Operation & Skull traction & Halo vest \\
\hline Number of patients & $\mathrm{n}=156$ & $\mathrm{n}=19$ & $\mathrm{n}=78$ & $\mathrm{n}=76$ \\
Displacement anteriorly or posteriorly & $10 \%$ & $58 \%$ & $33 \%$ & $39 \%$ \\
No displacement anteriorly or posteriorly & $90 \%$ & $42 \%$ & $67 \%$ & $61 \%$ \\
\hline
\end{tabular}

Table IV Cause of death

\begin{tabular}{lcl}
\hline Treatment & Days after trauma & \multicolumn{1}{c}{ Cause of death } \\
\hline Collar & 1 & $\begin{array}{l}\text { Bleeding in the nervous tissue of the medulla } \\
\text { Collar }\end{array}$ \\
Collar & 1 & $\begin{array}{l}\text { Multiple trauma, bleeding shock. Bleeding in the nervous } \\
\text { tissue of the medulla }\end{array}$ \\
Collar & 1 & Suicide. Multiple trauma. Bleeding shock \\
Collar & 1 & Suicide. Multiple trauma. Bleeding shock \\
Collar & 1 & Heart failure, complete A-V block \\
Collar & 10 & Cerebral haemorrhage \\
Collar & 10 & Pneumonia \\
Operation & 1 & Bleeding shock. Multiple trauma \\
Skull traction & 1 & Bleeding shock after operation \\
Skull traction & 19 & Septicaemia (diabetes mellitus) \\
Skull traction & 10 & Pneumonia (tetraparesis) \\
Skull traction & 137 & Pneumonia, during skull traction \\
& 86 & (Decubital ulcers). Septicaemia \\
Halo vest & 11 & Arteriosclerosis \\
Halo vest & 9 & Pulmonary embolism. Heart failure \\
\hline
\end{tabular}

Table $\mathbf{V}$ Complications of treatment associated with a Halo vest $(\mathrm{n}=76)$

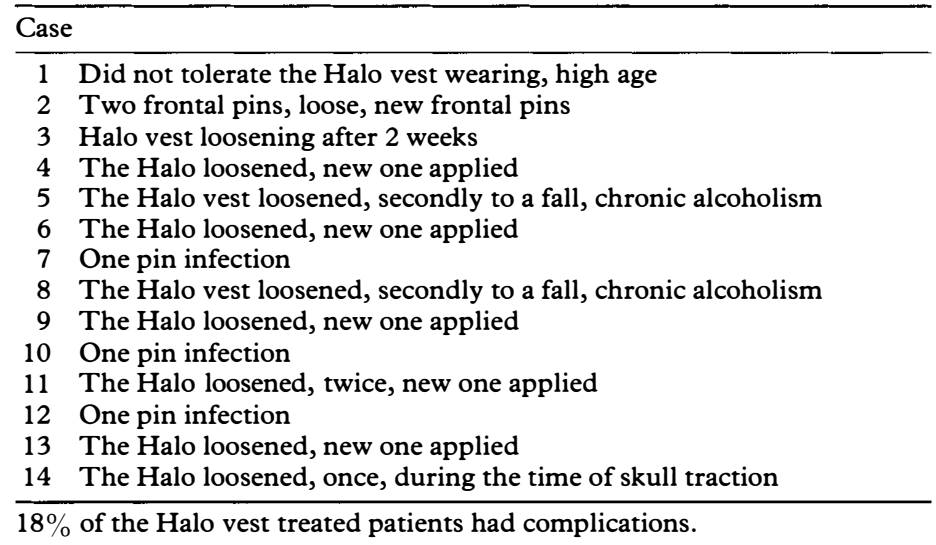

$58 \%$ respectively (Table VI, Table VII). The patients who had skull traction had a mean time of this for 26 days.

\section{The healing rate}

Five of the patients with a cervical spine injury did not have a healed spine. One patient with atlanto-axial instability without a fracture failed to heal, and a stabilising operation was added because of frequent cervical pain, there was no 
Table VI Complications associated with treatment using skull traction $(n=78)$

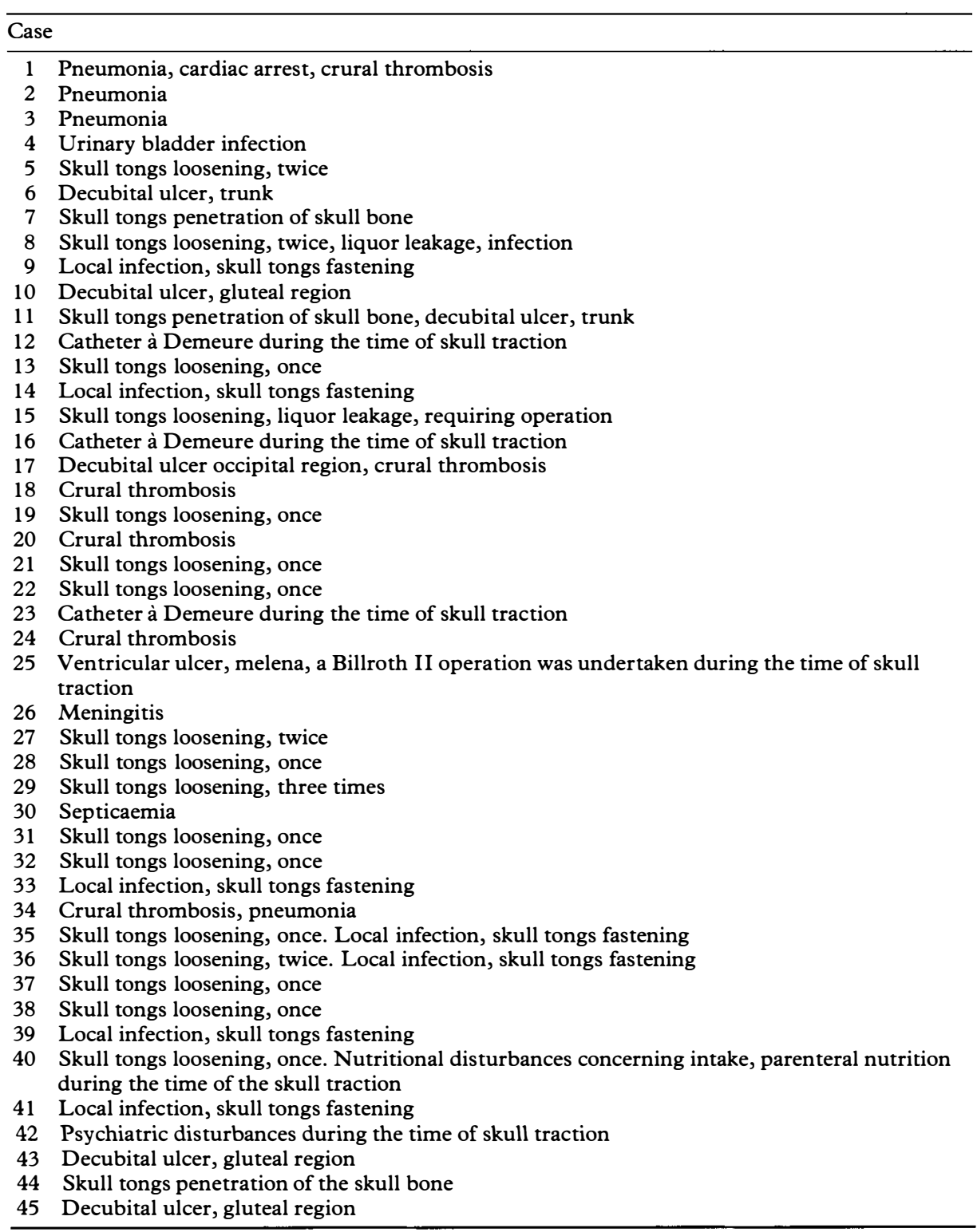

$58 \%$ of the skull traction treated patients had complications.

neurological impairment either before or after the operation. Because of incapacity for work the patient received a temporary disability pension. The other patients that failed to heal had an odontoid process fracture $5 / 115=4 \%$. Table VIII shows the treatment used when the spine failed to heal. In only one case of non-union was an operation added. In the group of dislocation injuries with fractured parts none was recorded as not healed. 
Table VII Complications associated with operative treatment $(n=22)$

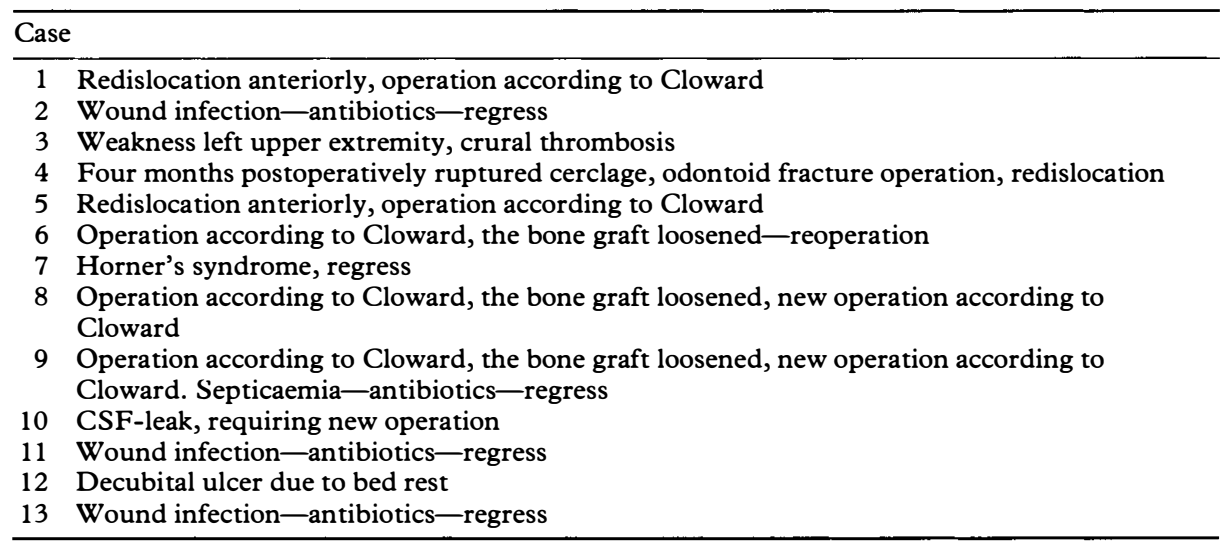

$59 \%$ of the operated patients had complications.

Table VIII Five fractures were not described as healed, all were odontoid process fractures

\begin{tabular}{lc}
\hline Treatment & Non-unions \\
\hline Collar & 3 \\
Operation & 0 \\
Skull traction & 1 \\
Halo vest & 1 \\
\hline
\end{tabular}

\section{Hospital and post-hospital treatments-sick leave-disability pensions}

Patients with Halo vest treatment had a very low use of hospital care in weeks and also of sick leave in days. This was further documented when the Halo vest treatment was compared with operation and skull traction (Fig. 7, Fig. 8).

Post-hospital treatment was necessary in $19 \%$ of patients treated with a collar, $74 \%$ of the operations, $43 \%$ of the skull traction, $29 \%$ of the Halo vest group. Regarding the necessity for a disability pension, it was found that patients who had an operation gave the highest percentage, $42 \%$. Next came skull traction $13 \%$, Halo vest $8 \%$ and collars $8 \%$.

\section{Discussion}

Little is known about the incidence of cervical spine injuries in earlier times, but during our 10-year follow-up there is a clear tendency to an increase of such patients (Fig. 1). This could to some extent be explained by increased intensity of traffic and by increased leisure. We also found a higher frequency of cervical spine injuries during holidays, June and July, and during the change-over to the dark season with snow and ice.

Older reports have given cervical spine injuries in the upper cervical block a bad reputation, although in later studies the mortality rates fell down to 5/63= 


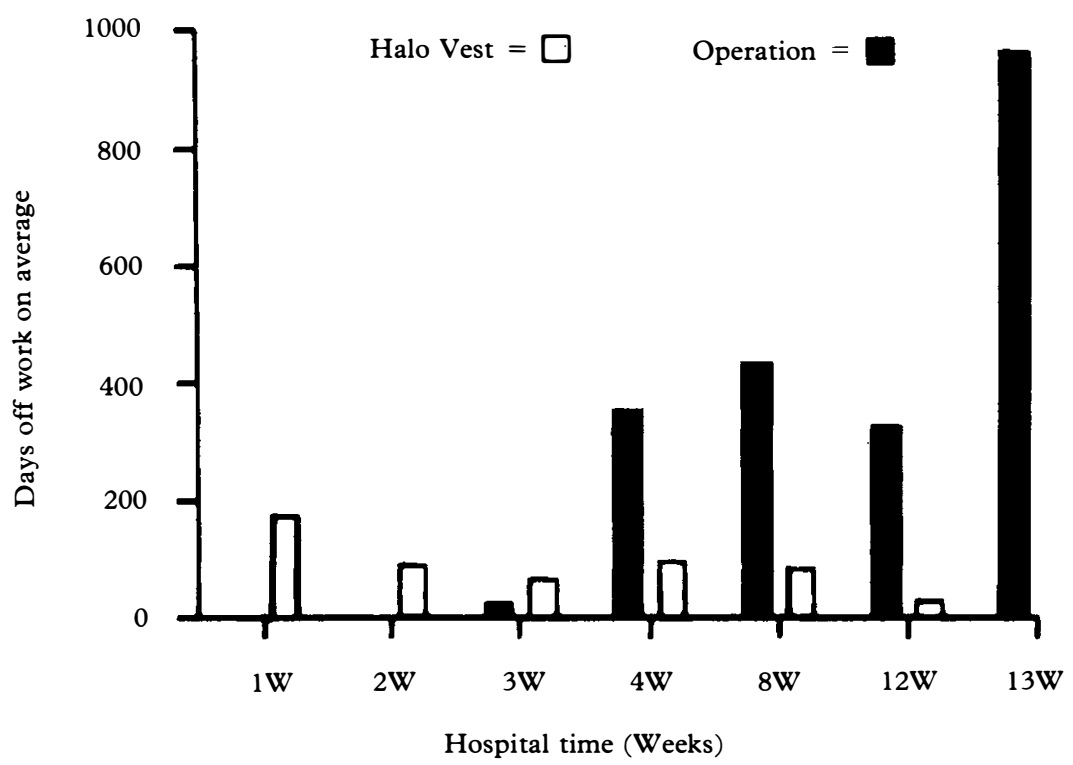

Figure 7 Halo vest treatment compared with operative treatment with respect to hospital time in weeks and sick leave in days on average. For instance, the Halo vest-treated patients who had been treated at the hospital for 4 weeks had on average 100 days off work compared with 350 days for the operative treated patients.

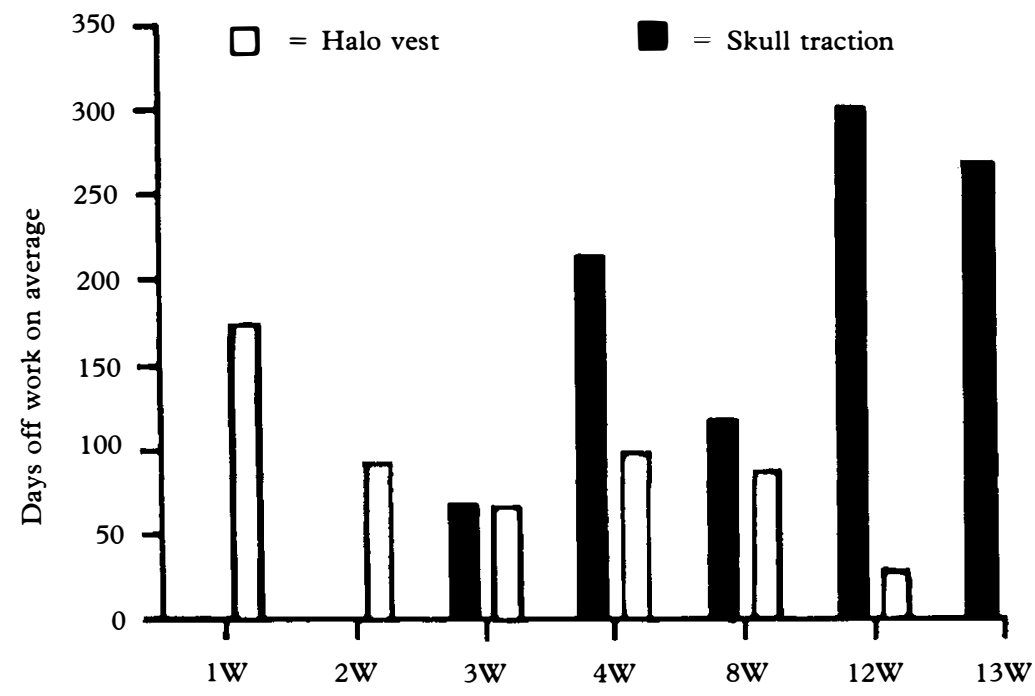

Hospital time (Weeks)

Figure 8 Halo vest treatment compared with skull traction treatment with respect to hospital time in weeks and sick leaves in days on average. For instance the Halo vest-treated patients who had been treated at the hospital for 4 weeks had on average 100 days off work compared with 225 days for the skull traction treated group of patients.

$8 \%$ (Amyes and Andersson, 1956), 14/77 = 18\% (Rogers, 1957), and $1 / 26=$ $4 \%$ (Nachemson, 1960), and 3/68 $=4 \%$ (Althoff, 1979), which corresponds to the $5 \%$ in this present study. The bad reputation also involved many results 
with high non-union rates for, in particular, conservatively treated odontoid process fractures. Variations ranged between 0-82\% (Althoff, 1979; Andersson and D'Alonzo, 1974), during the 1950s, 1960s and 1970s. This wide range may be due to variations in the conservative treatment and follow-up, but perhaps more to the fact that a review of the investigations of high non-union rates discloses rather few cases, and from this limited experience the authors categorically express their opinions or present misleading reviews of earlier investigations. In the present investigation of 332 patients, only 6 could be found who failed to heal. One patient had atlanto-axial instability (Halo vest treatment), and the other 5 patients had non-union odontoid process fractures $(5 / 115=4 \%)$. Three of those patients were treated with collars, 1 with skull traction, and 1 with a Halo vest.

The statement that an isolated fracture of the atlas is rather rare but by no means necessarily fatal (Jefferson, 1927; Hinchey and Bickel, 1945; Graubard and Ritter, 1949; Grogono, 1954; Seljeskog, 1978) accords with the present findings. The early statement by Jefferson in 1919 still holds: 'My first impression was that a fracture of the atlas would be almost invariably followed by death. Greater knowledge of the subject has, however, modified this opinion.'

Fractures of the neural arch, sometimes called Hangman's fracture or traumatic spondylolisthesis of the axis, are not very rare; they have a good prognosis and serious neurological damage is uncommon, 0-13 per cent, (Grogono, 1954; Schneider et al., 1965; Cornish, 1968; Brashear et al., 1975; Seljeskog, 1978; Effendi et al., 1981). These results are also corroborated by the present investigation, with $1 \%$ with serious neurological damage.

Isolated tears of the transverse ligament of the atlas (Gonzales et al., 1940; Hipp and Keyl, 1963) are very rare. It has been stated that these disruptions are most often fatal because of the danger of spinal cord damage. It is also obvious that an isolated rupture of the transverse ligament may readily be overlooked at post-mortem examination (Krantz and Löwenhielm, 1980). However, patients are described with these ruptures and survival (Dunbar and Bronson, 1961; Wigren and Amici, 1973; Fielding et al., 1974; Brunon et al., 19.78). Primary fusion has been recommended to avoid atlanto-axial instability. The Halo vest treated patient in the present investigation with an atlanto-axial instability that failed to heal was later stabilised operatively.

Cervical spine injuries in the lower cervical region have not received the same attention as cervical spine injuries in the upper cervical region. They are characterised by descriptions based on X-rays or classifications according to the assumed genesis (Cheshire, 1969; Holdsworth, 1970) and do not have as bad a reputation as injuries in the upper cervical region, but they may be associated with tetra- or paraparesis. In the present study injuries to the C5 level showed the most frequent association with tetraparesis.

Earlier descriptions of the localisation of fractures and fracture dislocation involving the cervical vertebrae (Amyes and Andersson, 1956; Nachemsson, 1960) showed a similar pattern but not to such a degree on the C2 level as in the present study. This accumulation of cervical spine injuries in the present study at the $\mathrm{C} 2$ level suggests this level to be a weak point. Odontoid process fractures consititute $35 \%$ of all cervical spine injuries in this study, compared with Amyes and Andersson's 13\% (1956) Injuries at the C2 level with regard 
to all fracture types in the present study constitute $48 \%$ compared with Hörlyck and Rahbeck's $31 \%$ (1974).

The age and sex incidence in some earlier investigation showed a predominance for men (Nachemsson, 1960; Hörlyck and Rahbeck, 1974) and also a peak age incidence around 20-40 years (Paradis and Janes, 1973; Hörlyck and Rahbeck, 1974). These differences have been further confirmed in the present study.

Traffic accidents constitute the main reason for cervical spine injuries, followed by falls (Amyes and Andersson, 1956; Roberts and Wickström, 1973; Paradis and Janes, 1973). Injuries from falls in our Swedish study show a predilection in those of older age, in contrast to traffic accidents which were associated with those of younger age. Diving accidents in the present series were uncommon and constituted 5\%. Other facts not previously described were that nearly all accidents (95\%) in our Swedish study occurred during leisure, and that $22 \%$ of the patients were under the influence of drugs and/or alcohol.

Mechanisms for the trauma level and incidence of neurological deficits might be:

1. The use and the types of safety belts, the condition of the vehicles, the maximum speed limits allowed and different traffic cultures concerning car accidents that may vary in different countries.

2. The influence of drugs and/or alcohol in this Swedish study which was about $20 \%$ may also vary in different countries.

3. The standard in the working environment varies too in different countries, just as does the relationship between working and leisure periods.

The site of the impact causing the patient's fracture was described in $42 \%$ of the medical records. The commonest result of the impact was an anterior cervical haematoma/excoriation, then a wound in the same location. Anterior displacement was more common than a posterior displacement, in analogy with earlier investigations (Blockey and Purser, 1965; Rogers, 1957; Schatzker et al., 1971; Roberts and Wickström, 1973; Paradis and Janes, 1973). An anterior impact to the vault of the head causes a transverse backward rotation of the head, which would favour an anterior displacement of upper cervical spine injuries. The direction of displacement has been discussed as a factor influencing the healing process of odontoid process fractures (Schatzker et al., 1971; Roberts and Wickström, 1973; Apuzzo et al., 1978). In this study, such a correlation could not be seen; this was also noted in the report by Althoff (1979).

Varieties of primary neurological impairment (paresthesiae, numbness, transient muscular weaknesses in the upper or lower extremities) were seen in $18 \%$ of the patients, whereas tetraparesis occurred in 5\%. In Rogers' series (1957) the figures were $64 \%$ and $20 \%$ respectively.

The primary neurological deficits and the concomitant injuries were not usually serious, except in a small group with primary severe neurological deficits of tetraparesis or paraparesis $(5 \%)$, and also a minor group $(4 \%)$ where the cervical spine injury was part of a multiple injury complex. This also corresponds to the earlier studies by Krantz and Löwenhielm (1980) where an Injury Severity Score around 25 has been calculated as a critical level for sur- 
vival. This also implies that there is a small group of patients with primary survival where improved emergency medical care can considerably reduce the number of fatalities. The survival prognosis, however, for most patients with upper cervical spine injuries is decided at the moment of trauma.

Cervical spine injuries and spinal cord injury can be missed in patients with multiple injuries, head injuries and in these without any paralysis (Ravichandran and Silver, 1982). In this study, a delay in making the diagnosis was found in $18 \%$, in two thirds of the patients it was due to 'patient's delay' and in the remaining third to 'doctor's delay'. This corresponds to the $4 \%$ doctor's delay described by Ravichandran and Silver (1982).

When analysing which factor might have governed the surgeon in the choice of treatment, displacement, neurological impairment or concomitant injuries, it was found that displacement was the most important.

Halo vest treatment gave a lower complication rate associated with treatment, a lower utilisation of hospital treatment, post-hospital treatment, sick leave and of disability pensions compared with patients who had an operation, and those having skull traction. The complication rate with Halo vest treatment was low in this series as compared to that of Garfin et al. (1986).

The complication rate for the skull traction and the operation groups was unacceptably high (Tables VI, VII). Crutchfield's programme of treatment (1954) with skull-traction for 6-10 weeks has not been fulfilled, as the skull traction time in the present study had a mean value of 26 days. The reason for this must be that the treatment could not be fulfilled because of the high rate of serious complications.

It could be claimed that patients treated by operation and skull traction were negatively selected. However, concerning concomitant injuries and neurological impairment, there were no differences between the different types of treatment. In the operated group there was a positive selection in younger patients and absence of contusio cerebri.

After reviewing this material of 332 patients with cervical spine injuries, we conclude that a collar is sufficient treatment for most undisplaced fractures, and that immobilisation by a Halo vest is an excellent method of treatment for most patients with a displaced fracture.

\section{References}

Althoff B, 1979 Fracture of the odontoid process. An experimental and clinical study. Acta Orthopaedica Scandinavica Supplement 177.

AMYes EW, ANDERSSON FM 1956 Fracture of the odontoid process. Archives of Surgery 72:377393.

ANDERSSON LD, D'ALONZo RT 1974 Fractures of the odontoid process of the axis. Fournal of Bone and foint Surgery 56-A:1663-1674.

Apuzzo MLJ, Heiden JS, ACKerson TT, et al. 1978 Acute fractures of the odontoid process. Fournal of Neurosurgery 84:85-91.

BAKER SP, O'NEILL B 1976 The injury severity score; an update. Fournal of Trauma 16:882.

BAKER SP, O'NeILl MPH, HADDON W, et al. 1974 The injury severity score: A method for describing patients with multiple injuries and evaluating emergency care. Fournal of Trauma 14:187.

BLOCKey NJ, PURSER DW 1965 Fractures of the odontoid process of the axis. Fournal of Bone and Foint Surgery 38:-B:794-817.

Brashear HR, Venters GC, Perston ET 1975 Fractures of the neural arch of the axis. Fournal of Bone and foint Surgery 57-A:879-887. 
Brunon J, Robin M, MANSUY L 1978 Les luxations atloido-axoidiennes traumatiques propos de deux observations a révélation tardive. Neurochirurgie 24:337-342.

CHESHIRE DJE 1969 The stability of the cervical spine following the conservative treatment of fractures and fracture-dislocations. Paraplegia 7:193-203.

ClowARD RB 1961 Treatment of acute fractures and fracture-dislocations of the cervical spine by vertebral body fusion. Fournal of Neurosurgery 18:201-209.

CONE W, TURNER WG 1937 The treatment of fracture-dislocations of the cervical vertebrae by skeletal traction and fusion. Fournal of Bone and foint Surgery 19:584-602.

CoOper PR, Maravilla KR, Sklar FH, et al. 1979 Halo immobilization of cervical spine fractures. Fournal of Neurosurgery 50:603-610.

CoRNISH BL 1968 Traumatic spondylolisthesis of the axis. Fournal of Bone and foint Surgery 50B:31-43.

CRUTCHFIELD WG 1933 Skeletal traction for dislocation of the cervical spine. South. Surg. 2:156-159.

CRUtChField WG 1954 Skeletal traction in treatment of injuries to the cervical spine. Jama 155:29-32.

DUNBAR HS, BRONSON SR 1961 Chronic atlanto-axial dislocations with late neurologic manifestations. Surgery, Gynecology and Obstetrics 113:757-762.

EFFENDI B, ROY D, CORNISH B, et al. 1981 Fractures of the ring of the axis. Fournal of Bone and foint Surgery 63-B:319-327.

Fielding JW, Cochran GVB, LAwsing JF, et al. 1974 Tears of the transverse ligament of the atlas. Journal of Bone and Joint Surgery 56-A:1683-1691.

FriTZSCHE E 1913 Über die Frakturen des Zahnfortsatzes des Epistropheus. Neue röntgenographische Darstellung des Processus Odontoideus. Deutsche Zeitschrift für Chirurgie 120:7-34.

GALLIE WE 1939 Fractures and dislocations of the cervical spine. American fournal of Surgery 46:495-499.

Grafin SR, Botte MJ, Waters RL, et al. 1986 Complications in the use of the Halo fixation device. Fournal of Bone and Foint Surgery 86-A:319-315.

Gonzales TA, Vance M, Helpern M, et al. 1940 Legal Medicine: Pathology and Toxicology. Appleton Century Crofts, New York. p 312.

Graubard DJ, RitTer HH 1949 Isolated fracture of the atlas. Annals of Surgery 130:261-266.

Grogono BJS 1954 Injuries of the atlas and axis. Fournal of Bone and foint Surgery 36-B:397410.

Hinchey JJ, Bickel WH 1945 Fracture of the atlas. Annals of Surgery 121:826-832.

HIPP E, KEYL W 1963 Frakturen an Atlas und Axis. Fortschritte Medizin 81:589-596.

HOLDSWORTH F 1970 Fractures, dislocations and fracture-dislocations of the spine. Fournal of Bone and foint Surgery 52-A:1534-1551.

HÖRLYCK E, RAHBECK M 1974 Cervical spine injuries. Acta Orthopaedica Scandinavica 45:845853.

JEFFERSON G 1920 Fracture of the atlas vertebra. British fournal of Surgery 7:407-422.

JEFFERSON G 1927 Fractures of the first cervical vertebra. British Medical fournal 30:153-157.

KRANTZ KPG 1980 Isolated disruption of the transverse ligament of the atlas: An injury easily overlooked at post-mortem examination. Injury 12:168-170.

KRANTZ KPG, LOWENHIELM CGP 1980 Injury response in belted and unbelted car occupants related to the car crash energy in 458 accidents. Proceedings V Int IRCOBI conference, Birmingham: 305-317.

Mixter SJ, Osgood RB 1910 Traumatic lesions of the atlas and axis. Annals of Surgery 51:193-207.

Nachemson A 1960 Fracture of the odontoid process of the axis. Acta Orthopaedica Scandinavica 29:185-217.

Nickel VL, Perry J, Garret, A et al. 1968 The Halo. Fournal of Bone and foint Surgery 50A:1400-1409.

OsGood RB, LUND CC 1928 Fractures of the odontoid process. New England fournal of Medicine 198:61-72.

PARADIS GR, JANES JM 1973 Posttraumatic atalantoaxial instability: the fate of the odontoid process fracture in 46 cases. Fournal of Trauma 13:359-367.

PERRY J, NICKel VL 1959 Total cervical spine fusion for neck paralysis. fournal of Bone and foint Surgery 41-A:37-60.

RAVICHANDRAN G, Silver JR 1982 Missed Injuries of the spinal cord. British Medical fournal 284:953.

Roberts A, Wickström J 1973 Prognosis of odontoid fractures. Acta Orthopaedica Scandinavicae 44:21-30.

ROGERS, WA 1957 Fractures and dislocations of the cervical spine. An end result study. Fournal of Bone and foint Surgery 39-A:341-376. 
SChatZKer J, RoRABECK CH, WAdELl JP 1971 Fractures of the dens (odontoid process). An analysis of thirty-seven cases. Fournal of Bone and Foint Surgery 53-B:392-405.

SCHENIDER RC, LIVINGSTONE KE, CAVE AJE et al. Hangman's fracture of the cervical spine. Fournal of Neurosurgery 22:141-154.

SELJESKOG EL 1978 Non-operative management of acute upper cervical injuries. Acta Neurochirurgica 41:87-100.

Thомpson H 1962 The 'Halo' traction apparatus. A method of external splinting of the cervical spine after injury. Fournal of Bone and foint Surgery 44:-B:655-661.

VERBIEST H 1969 Anterolateral operations for fractures and dislocations in the middle and lower parts of the cervical spine. Fournal of Bone and foint Surgery 51-A:1489-1530.

WIGREN A, AMICI F 1973 Traumatic atlantoaxial dislocation without neurological disorder. fournal of Bone and foint Surgery 55-A:642-644. 